\title{
Shorting And Drying Technology Unit For Improving The Effectiveness Of Black Onion Process
}

\author{
Kerista Sebayang $^{1 *}$, Amir Hamzah Siregar ${ }^{2}$, Herty Afrina Sianturi ${ }^{1}$, Erni Misran ${ }^{3}$ \\ ${ }^{1,}$ Departments of Physics, Faculty of Mathematics and Natural Science, Universitas Sumatera \\ Utara \\ ${ }^{2}$ Departments of Chemistry, Faculty of Engineering, Universitas Sumatera Utara \\ ${ }^{3}$ Departements of Chemical Engineering, Faculty of Engineering, Universitas Sumatera \\ Utara \\ *Email: keristasebayang@usu.ac.id
}

\begin{abstract}
In 2016, the development of Gempar Tunggal Micro Small and Medium Enterprises (MSMEs) that involved in the processing of black onions began. The raw materials are obtained from the Medan City market center, but sometimes it also come from Brebes and Semarang. The goods manufacture that resulted are sold to Aceh, Kalimantan and Sulawesi. However, because it was a home industry, the manufacturing system that was developed still very simple. Therefore, some weakness were identified, in particular the percentage of damaged or defective finished goods reaching 25 percent before its sold, various levels of maturity and work processes and supervision that drained attention and energy. In addition, the cost of using electricity is also high. It was found from the literature study by the Abdimas team of USU that there are 3 parameters that affect the processing of onions, namely garlic which is sensitive to temperature, humidity and exposure period of temperature and humidity. Often, due to the unequal size of the raw onion amount, the maturity of the onions is not homogenous distributed made the bigger the raw material of the onion impacted the faster it will ripen. Another problem that found during manufacturing process is the water vapor was not completely evaporated from the furnace. Basic technology that was developed by Abdimas USU team, namely the manual gravity onion sorting and drying unit was already used by Partners in the production process. As the result, it was successfully reducing broken onions. Lastly, homogenous maturity due to dividing process the onions by scale obtained.
\end{abstract}

Keyword: Micro enterprises, black onion, sorting unit, dryer

\begin{abstract}
Abstrak
Produksi Usaha Mikro Kecil Menengah (UMKM) Gempar Tunggal yang bergerak di bidang pengolahan bawang hitam dimulai tahun 2016. Bahan baku diperoleh dari pusat pasar di Kota Medan namun terkadang berasal dari luar daerah seperti Brebes dan Semarang. Hasil produksi yang telah diolah dijual ke Aceh, Kalimantan dan Sulawesi. Namun sistem produksi yang dibangun masih sangat sederhana berbasis industri rumah tangga sehingga ditemukan berbagai kelemahan terutama persentasi angka produk akhir yang rusak atau pecah mencapai 25\% sebelum dipasarkan, tingkat kematangan yang berbeda-beda dan proses kerja serta pengawasan yang menguras perhatian dan tenaga. Selain itu, biaya pemakain listrik juga tinggi. Dari studi pustaka yang oleh tim Abdimas USU, didapatkan bahwa ada 3 parameter yang berpengaruh pada pengolahan bawang, yaitu bawang putih sensitif terhadap suhu, kelembaban udara dan durasi paparan suhu dan kelembaban. Kematangan bawang juga yang masih kurang merata disebabkan oleh ukuran bahan volume baku bawang yang tidak rata sehingga semakin kecil bahan baku bawang maka semakin cepat matang. Pekerjaan yang menguras perhatian pada saat pengolahan adalah masih ditemukannya uap air yang tidak menguap sempurna dari tungku produksi. Teknologi sederhana dibuat oleh tim abdimas USU yaitu unit sortir bawang manual grafitasi dan unit pengering telah digunakan oleh mitra dalam proses produksi. Hasil yang cukup efisien dalam mengurangi bawang pecah pada proses pengeraman bawang. Kemudian terjadinya kematangan yang merata dengan memisahkan bawang terlebih dahulu berdasarkan ukuran.
\end{abstract}

Kata Kunci: Usaha mikro, bawang hitam, unit sortir, alat pengering 


\section{PENDAHULUAN}

UMKM Gempar Tunggal adalah industri rumah tangga yang bergerak pada bidang pengolahan bawang putih tunggal. UMKM ini menjadi mitra pada Program Pengabdian Kepada Masyarakat Universitas Sumatera Utara selama 2 tahun dan akan dimulai pada tahun 2020, khususnya pada pembenahan teknologi alat-alat produksi. Mitra sudah merintis usaha ini sekitar lima tahun yang lalu, diawali dengan berbagai percobaanpercobaan sendiri hingga mendapatkan proses pengolahan yang baik, mendesain sendiri alat sederhana yang disesuaikan dengan pola pengolahan. Mitra juga telah mengenali bahan baku yang dapat memenuhi kualifikasi yang diinginkan (Gambar-1a). Bawang hitam telah lama dikenal di tengah masyarakat terutama golongan menengah ke atas sebagai suplemen kesehatan. Peningkatan bioaktivitas bawang putih hitam dibandingkan dengan bawang putih segar dikaitkan dengan perubahan sifat fisikokimianya (Kimura dkk, 2016). Oleh masyarakat bahkan sering dipergunakan untuk terapi penyakit-penyakit kronis seperti darah tinggi, jantung, diabetes, kanker, badan lesu dan lemah, dan lain sebagainya (Onuora dkk, 2019). Mitra mendapatkan bawang putih tunggal di pasar pusat Kota Medan, telah memiliki tiga grosir pemasok tetap. Bila kekurangan suplai bahan baku terjadi, mitra mendapatkannya dari Brebes dan Semarang. Suplai bahan baku berkurang di pasar pusat Kota Medan sebenarnya lebih disebabkan pemilihan bawang yang ketat oleh mitra dan segar. Hasil ini menunjukkan bahwa BG dapat tidak hanya memiliki sifat antioksidan selama periode penuaan, tetapi juga mencapai sifat antioksidan optimal pada hari ke-21 penuaan (Choi dkk, 2016).

Sebelum diolah, bawang terlebih dahulu dibersihkan dari tanah dan kulit-kulit yang sudah hampir lepas (Gambar-1b). Bila ada akar panjang yang masih menempel harus digunting, demikian juga kulit daun yang masih panjang. Kemudian bahan baku dimasukkan ke dalam alat pengolahan (Gambar-1c), diperiksa setiap 3 hari untuk memastikan mutu yang dihasilkan. Kualitas standar yang menjadi pedoman mitra adalah (1) warna harus hitam kecoklatan (very dark brown) namum bukan hitam legam, (2) rasa harus kemanis-manisan, keasam-asaman dan kepahit-pahitan serta keasin-asinan, (3) bau bawang telah hilang, (4) tidak ada bau yang lain seperti bau karet ban, bau belerang dan sebagainya, (5) tekstur tidak terlalu kenyal dan tidak terlalu lunak. Untuk proses ini diperlukan waktu hingga 3 minggu Setelah semua matang, bawang hitam disortir diantara yang pecah dengan yang tidak pecah (Gambar-1d). Produk akhir yang pecah disisihkan dan yang masih utuh kemudian dimasukkan ke dalam toples dan siap untuk dikirim kepada pembeli (Gambar1e). Selain menjual langsung melalui media sosial, mitra juga memiliki dua agen yang menjual ke Aceh, Kalimantan dan Sulawesi. 


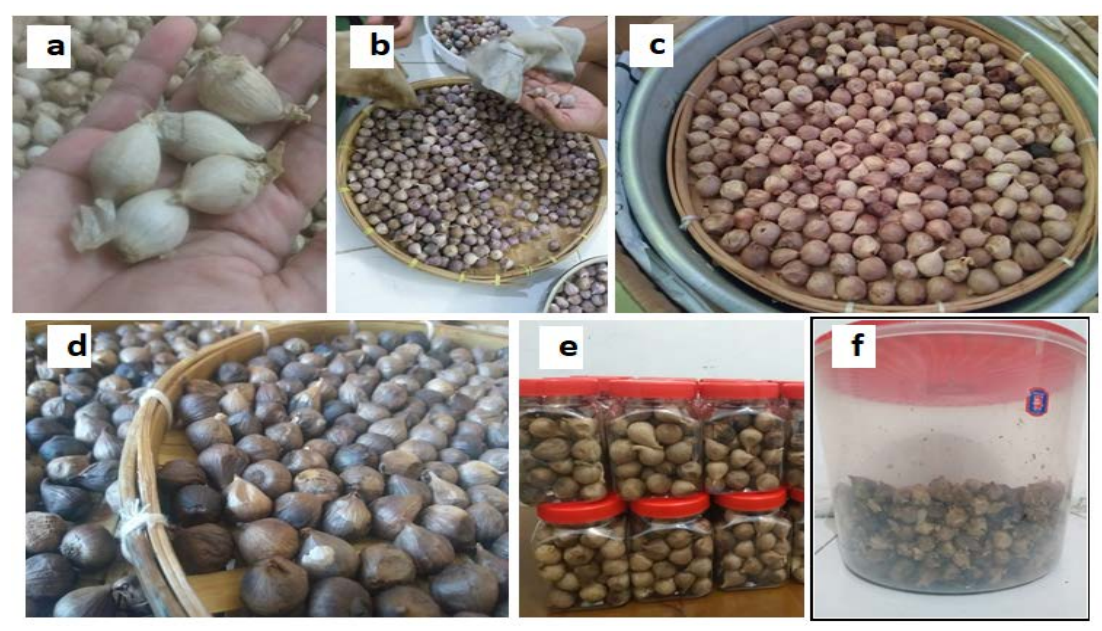

Gambar 1. Urutan pekerjaan memproduksi bawang hitam (a) Pemilihan bahan baku, (b) pembersihan bahan baku, (c) memasukkan ke dalam alat, (d) sortir hasil produksi rusak, (e) pengemasan hasil produksi, (f) hasil produksi rusak.

Pengolahan bawang tunggal ini juga ternyata mitra menghadapi beberapa masalah untuk efisiensi produksi yaitu kulit bawang pecah, rasa yang tidak rata, ukuran bahan baku yang tidak sama, pengaturan suhu dan kelembaban, biaya listrik yang lumayan mahal, proses pengeringan pada akhir proses produksi. Kemudian masalah yang dihadapi oleh mitra juga meliputi standar Good Manufacturing Practice, sehingga produksi dapat memenuhi standar BPOM dan halal MUI.

\section{METODE PELAKSANAAN}

Tim abdimas USU membantu UMKM Gempar Tunggal untuk efisiensi dan peningkatan mutu produksi hitam. Metode yang akan dilakukan pada pelaksanaan pengabdian ini adalah:

2.1. Pembuatan unit sortir bawang manual grafitasi

Unit sortir didesain dan dibuat tidak diberikan getaran mekanis dengan maksud menghindari benturan antar bahan. Cara kerjanya adalah meletakkan bahan baku pada bagian sempit lalu didorong dengan tangan menuju bagian yang melebar. Perbedaan ukuran celah akan melewatkan bahan baku secara berturut-turut sesuai dengan ukuran.

\subsection{Pembuatan unit pengering}

Unit pengering ini adalah alat pada pengolahan tahap ketiga. Proses tahap ketiga selama ini dilakukan pada alat yang sama dengan tahap-1 dan tahap-2. Bahan-bahan yang digunakan pada pembuatan alat ini adalah plat aluminium untuk kebutuhan pelapisan dalam dan luar. Diantara lapisan diberikan glass wool sebagai isolator panas sehingga energi yang terbuang pada lingkungan dapat diperkecil, diberikan jalur pengeluaran upa air pada bagian tutup. Elemen pemanas dipasang pada selubung dalam dan selubung bawah. Alat ini dilengkapi denga PID control untuk mengontrol suhu. 


\subsection{Penyuluhan Implementasi IPTEK}

Berdasarkan permasalahan yang telah diidentifikasi pada mitra, metode pendekatan yang digunakan adalah memperkenalkan dasar-dasar pengolahan bawang hitam dan pengarahan penggunaan dan pemeliharaan alat. Secara rinci, langkah-langkah yang akan dilakukan tim Abdimas USU bersama mitra sebagai berikut:

1. Menjelaskan parameter dasar dalam pengolahan bawang.

2. Menjelaskan fungsi alat pengering yang berhubungan dengan masalah-masalah yang dihadapi mitra.

3. Menjelaskan SOP mengoperasikan alat.

4. Menjelaskan bagaimana cara pemeliharaan alat.

\section{HASIL DAN PEMBAHASAN}

\subsection{Berkurangnya jumlah bawang pecah}

Bahan baku yang telah disortir untuk dijadikan bahan produksi (Gambar 2a). Hal yang paling dirasakan oleh mitra adalah jumlah bawang pecah berkurang sangat drastis kurang dari 5\%. Hal ini terjadi karena pada tahap ketiga dimana kulit bawang mengeras dan rapuh, dilakukan tidak berlapis-lapis atau tumpang tindih. Satu rak memuat bawang hingga $12 \mathrm{~kg}$, maka total yang dapat dikeringkan adalah $24 \mathrm{~kg}$ dalam satu waktu, sehingga percepatan produksi lebih baik.

\subsection{Kematangan merata dan lebih konsisten}

Bila dalam seminggu reaksi Maillard tidak terpicu, biasanya bawang menjadi melunak seperti karet, warna coklat muda dan pahit dan bawang sudah tidak dapat diolah lebih lanjut karena hasil akhirnya adalah menghitam dan keras seperti batu. Setelah menggunakan desain dengan pengontrol suhu yang stabil, kematangan bawang lebih cepat. Konsisten dalam waktu 4 hari bawang sudah mulai mengeluarkan air secara merata sebagai pertanda bahwa reaksi Maillard sudah mulai terjadi. Pada hasil akhir terlihat bawang memiliki rasa yang lebih merata dan dimasukkan kedalam wadah siap dipasarkan (Gambar 2b).

\subsection{Penyuluhan dan sosialisasi tim abdimas USU}

Proses pelaksanaan kegiatan pengabdian masyarakat juga tetap memberikan penyuluhan dan sosialisasi kepada mitra, agar selalu memperhatikan parameter dasar dalam pengolahan bawang. Pengoperasian dan pemeliharaan peralatan juga disampaikan sehingga alat yang ada terpelihara dengan baik (Gambar 2c).

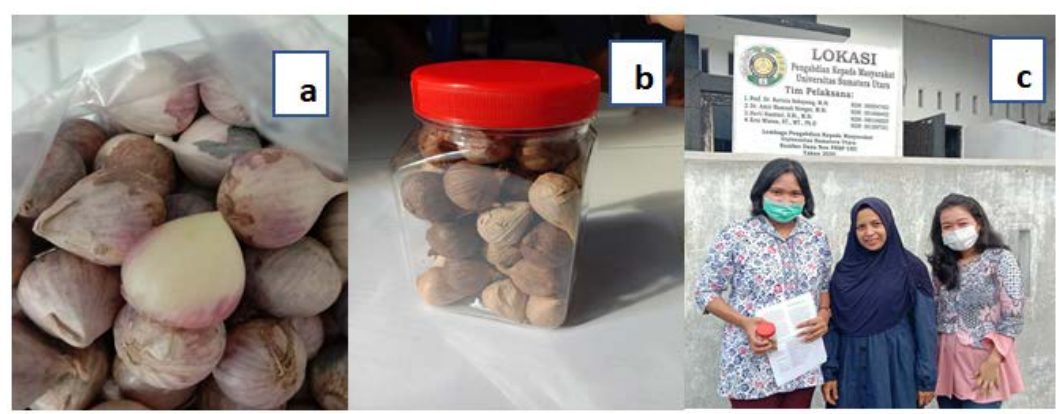

Gambar 2. a. Hasil bawang tunggal yang telah disortir b. Hasil bawang hitam yang telah dikeringkan dan telah siap dikonsumsi c. Tim Abdimas USU di Lokasi Pengabdian bersama mitra 


\section{KESIMPULAN}

Pelaksanaan pengabdian masyarakat ini tim menyimpulkan bahwa :

Penggunaan unit sortir dan unit pengering dapat mengurangi lapisan bawang yang terkelupas atau pecah pada proses pengeraman bawang. Kematangan bawang hitam yang merata dapat dilakukan dengan memisahkan bawang terlebih dahulu berdasarkan ukuran.

\section{UCAPAN TERIMAKASIH}

Tim pengabdian menyampaikan terimakasih kepada Rektor Universitas Sumatera Utara melalui lembaga pengabdian masyarakat atas program multi tahun dana NON PNBP Universitas Sumatera Utara Nomor: 288/UN5.2.3.2.1/PPM/2020. Tim juga menyampaikan terimakasih kepada mitra pada kegiatan pengabdian ini.

\section{DAFTAR PUSTAKA}

Onuora Chidinma, Ofili C Timothy, Salawu Samuel, Elimian Isaac and Shehu Hauwa, 2019, Therapeutic Effects of Garlic: A Review, Sci J Biol \& Life Sci. 1(1): 2019. SJBLS.MS.ID.000502.

Shunsuke Kimura, Yen-Chen Tung, Min-Hsiung Pan, Nan-Wei Su, Ying-Jang Lai, KuanChen Cheng, 2016, Black garlic: A critical review of its production, bioactivity, and application, Journal of food and drug analysis (2016) I-9.

Sook Choi, Han Sam Cha, Young Soon Lee, 2014, Physicochemical and Antioxidant Properties of Black Garlic, Molecules 2014, 19, 16811-16823. 